\title{
SPME Extraction Methods of Doped Organochlorine Pesticides in Moroccan Water Samples
}

\author{
Ahmed Lakhili ${ }^{1,2, *}$, Mohammed Fekhaoui ${ }^{1,2}$, Abdelkbir Bellaouchou ${ }^{3}$, Abdellah El Abidi ${ }^{2}$ \\ and Latifa Tahri ${ }^{2}$ \\ ${ }^{1}$ Laboratoire d'Hydrologie, d'Hygiene Industrielle et Environnementale, \\ Institut National d'Hygiene, Rabat Maroc \\ ${ }^{2}$ Institut Scientifique de Rabat, Université Mohammed V, Rabat, Maroc \\ ${ }^{3}$ Departement de Chimie, Faculté des sciences de Rabat, Université Mohammed V, Rabat, Maroc
}

\begin{abstract}
To investigate Organochlorine (OC) in Moroccan water samples, two different methods of extraction being the solid phase micro extraction (SPME) and the liquid-liquid extraction (LLE) are exploited. The gas chromatography with an electron capture detector (GC-ECD) and the gas chromatography coupled to a mass spectrum (GC-MS) are elaborated. In order to get the best extraction, different process parameters are cheeked and optimized. The relevant results are obtained using a time of unspecific binding properties of 30 minutes' duration and mode of agitation for $30 \mathrm{~min}$ with agitation by a magnetic stirrer and a temperature of $30{ }^{\circ} \mathrm{C}$. In particular, a comparative study between the results of SPME and LLE coupled to (GC-ECD) and (GC-MS), respectively, are given. Concretely, it has been found that the SPME extraction technique is a very useful method to analyze the pesticide residues in water samples controlled by local laboratories.
\end{abstract}

Keywords: Organochlorine Pesticides, SPME, LLE, Optimization, Extraction Yield, Water samples

\section{Introduction}

Pesticides are compounds characterized by their diversity and their different physicochemical properties ${ }^{1}$. Their adverse side effects have been quickly identified. The toxicity related to their molecule structures is not limited due to those species which should be removed. They are particularly toxic not only to humans ${ }^{2,3}$ but also to the environment. Such molecules tend to accumulate in different biotic and abiotic matrices, including water, air, soil, aquatic organism, and food 4-14. More precisely, organochlorine (OC) pesticides are among the oldest organic synthetic ones being used in agriculture in the world since 1940 because of their strong impact in the fight against pests and diseases ${ }^{6,7}$. However, OC's are very toxic and persistent in the environment which tends to accumulate in living organisms. Following low degradation and high solubility in organic materials, they easily enter the food chain as contaminants reaching humans through the consumption of drinking water and agricultural food products ${ }^{8,9}$. Although most of them have been banned from use, they are still detected in ecosystems [4-1]. It has been shown that OC's are very sparingly soluble or insoluble molecules in water, but very soluble in nonpolar organic solvents and especially lipids ${ }^{11,12}$.
Recently, the analysis of OC pesticide residues has received increasing attention, including in Morocco. It has been remarked that the OC' monitoring in water samples is very important and requires high efficiency, unique selectivity, and high sensitivity techniques ${ }^{15,16}$.

It turns out that liquid/liquid extraction (LLE) is used to extract chemical molecules into an organic solvent. This method is applied to a variety of specimens including blood, urine, bile, gastric contents, and tissue homogenates and acidic. The chemical properties of pesticides can be used to select such organic solvents to perform a successful extraction from a biological sample. However, the disadvantage of LLE is that relatively large volumes of organic solvents are required. This leads to problems. Also, this technique requires a good analysis for dealing with such a method.

In Asia, a new liquid-liquid extraction method has been developed and validated to determine montelukast in human plasma with small plasma sample volume with fluorescence detection. It has been shown that this method is specific with costeffective which can be used for quantitative analysis of such chemical samples of new scientific developments in the area of Analytical 
Chemistry ${ }^{17,18}$. Moreover, the introduction of SPME coupled with sample preparation GC / MS enabled high throughput extraction and specimen preparation for this SPME geometry, broadening its applicability to a variety of bioanalytical assays ${ }^{19,20}$.

This work aims to contribute to these scientific activities by considering two different methods of OC extraction namely solid phase microextraction (SPME), and liquid-liquid extraction (LLE) coupled to the gas chromatography with electron detectors (GC-ECD) in order to determine OC's in the water samples. In this paper, we first investigate the OC detection by the LLE technique. Then, we study the absorption and the desorption of OC by the SPME technique. The main objective of this work is to compare the results of SPME and LLE coupled to (GC-ECD) and (GC-MS), respectively. In particular, it has been shown that the SPME extraction technique is considered as a very useful method for the analysis of pesticide residues in water samples dealt with certain Moroccan medico-legal laboratories.

\section{Materials and methods}

\section{Preparation of injection solutions}

In this work, we prepared two standards solutions of $100 \mu \mathrm{g} / \mathrm{L}$ each containing a mixture of five organochlorines. The standard solutions were provided by Promochem. The purity of the residues varies between $96 \%$ and $99.8 \%$. All CO's were diluted in HPLC grade hexane Dichloro diphenyldichloroethane (DDD), dichlorodiphenyldichloroethylene (DDE), endrin, adrin and endosulfan are named "Mixture I" and the one containing dichlorodiphenyltrichloroethane (DDT), lindane, dentifrin, endosulfan sulfate and $\beta$-endosulfan is called "Mixture II".

The used solvent was hexane. The two solutions "Mixture I" and "Mixture II" were diluted in order to prepare the solutions at different concentrations $(0.1$, $0.5,1,2,3$ and $5 \mu \mathrm{g} / \mathrm{L})$. The matrix used in the present investigation is the urban water distribution networks.

\section{Determination of the retention time}

The determination of the retention time for each injected chemical sample is performed by $1 \mu \mathrm{L}$ glass syringe injected directly into the GC-ECD injector. It is recalled that the injector cleaning is necessary to eliminate any risk resulted from the interaction between molecules.

The starting temperature is $70{ }^{\circ} \mathrm{C}$ with a flow rate of $2.4 \mathrm{~mL} / \mathrm{min}$. The oven temperature is set at $2{ }^{\circ} \mathrm{C} /$ min until reaching $260^{\circ} \mathrm{C}$. Moreover, the temperature of the injector is about $250{ }^{\circ} \mathrm{C}$. While, the temperature of the detector is around $300{ }^{\circ} \mathrm{C}$.

\section{Liquid-liquid extraction method (LLE)}

Before starting the tests, an analysis of the water

matrix, with no pre-treatment by LLE and SPME, is elaborated in order to eliminate the possibility of the presence of chemical molecules that could interact with doped OC's distorting the yield profiles.

Before proceeding with LLE, we collected at the level of Urban Water Distribution Networks in the capital city of Morocco (Rabat). In particular, we considered 1 liter of water for each concentration. We have doped each liter of analyzed water to extract pesticides with $1 \mathrm{~mL}$ of the "mixture I" solution and the "Mixture II" solution. These solutions are introduced into a separating funnel with $100 \mathrm{ml}$ of hexane. After manual stirring for $10 \mathrm{~min}$, we recovered the organic phase of each solution in a flask to which we added a few grams of anhydrous sodium sulfate. This step is relevant to remove any traces of the aqueous phase in the recovered two organic solutions. We proceeded to a second extraction of the aqueous phase by adding $50 \mathrm{~mL}$ of hexane. The recovered organic phase is added to the first one obtained from the first extraction. They are concentrated using the rotary evaporator under vacuum at $40{ }^{\circ} \mathrm{C}$ until a final volume of $5 \mathrm{~mL}$. It is important to note that this double extraction is necessary to recover all molecules present in the solutions and not to disadvantage one technique concerning the other. To detect and quantify the appeared OC molecules in the concentrated organic solutions $(5 \mathrm{~mL})$, we injected directly $1 \mu \mathrm{L}$ of each solution into the GC-ECD injector. This operation was carried out for each concentration $(0.1,0.5,1,2$, 3 and $5 \mu \mathrm{g} / \mathrm{L}$ ) and both mixtures (I and II). The analysis conditions are the same as the one used for determining the retention time.

Here, we list the chromatography conditions:

- Colum Initial temperature: $70^{\circ} \mathrm{C}$

- Oven programming: $2{ }^{\circ} \mathrm{C} / \min$ up to $260{ }^{\circ} \mathrm{C}$

- Final temperature: $260{ }^{\circ} \mathrm{C}$ for $15 \mathrm{~min}$

- The flow rate of the column: $2.4 \mathrm{~mL} / \mathrm{min}$

- Vector gas: N2 nitrogen

- Injection temperature: $250{ }^{\circ} \mathrm{C}$

- Injection mode: splitless

- Detector used: ECD

- Detector temperature: $260{ }^{\circ} \mathrm{C}$

- $\quad$ injected Volume: $1 \mathrm{Ml}$

\section{Solid phase microextraction method}

An experimental protocol has been established for the detection and quantification of OC molecules of the organic solution for both mixtures by the solid phase microextraction method (SPME), we immersed the SPME fiber in the same organic solutions used in the previous method (LLE). This step was carried out at the room temperature for 15 minutes. The used fiber consists of a Carboxen/ PDMS/ DVB 50/30 $\mu$ m phase.

The chemical compounds are first concentrated on the fiber (adsorption phase). Then they are thermally desorbed in the GC-ECD injector. The analysis conditions are the same as the ones mentioned above. 


\section{Optimizing SPME}

To increase the sensitivity and the effectiveness of the SPME method, we considered an optimization of various parameters including the temperature, the exposure time, the duration and the mode of agitation, the effect of the $\mathrm{pH}$ and adding salt.

\section{Calculation method}

The concentration of the OC's is determined according to the method of qualification of the peaks taking into account the volume of final extract and the volume of analyzed water for each identified molecule. Using the appropriate equations, the concentration for the LLE method reads as

$C e=\frac{A s t}{A e} \times C i \times \frac{V e}{V}$.

Wile for SPME method, it is given by

$C e=\frac{A e \times C i}{A s t}$
Where $\mathrm{Ce}$ is the concentration of a compound in the sample. Ae indicates the air of a compound in the sample. As it is the air of a compound in the standard. $\mathrm{Ci}$ represents the initial concentration of a compound in the standard and $\mathrm{V}$ denotes the volume of the sample of water to be dosed in ml. Ve is the volume of extract in $\mathrm{ml}$. The percent recovery (PR\%) or yield of each compound was calculated using the peak air. Concretely, this has been done using the following equation

$\mathrm{PR}=\frac{\mathrm{Ce}}{\mathrm{Ci}} \times 100$

Where Ce now represents the concentration of the sample and where $\mathrm{Ci}$ denotes the standard initial concentration. More details on the calculations can be found ${ }^{18}$.

Table I. Extraction yield by LLE and SPME.

\begin{tabular}{|c|c|c|c|c|c|c|}
\hline Conc $(\mu \mathrm{g} / \mathrm{L})$ & 0.1 & 0.5 & 1 & 2 & 3 & 5 \\
\hline \multirow{2}{*}{ Aldrine } & ND & ND & $45 \%$ & $60 \%$ & $97 \%$ & $100 \%$ \\
\hline & $\mathrm{ND}$ & $\mathrm{ND}$ & $38 \%$ & $61 \%$ & $100 \%$ & $90 \%$ \\
\hline \multirow{2}{*}{$\alpha$-Endosulfan } & ND & ND & $42 \%$ & $56 \%$ & $78 \%$ & $80 \%$ \\
\hline & $\mathrm{ND}$ & $\mathrm{ND}$ & $44 \%$ & $59 \%$ & $73 \%$ & $68 \%$ \\
\hline \multirow{2}{*}{ DDE } & ND & ND & $50 \%$ & $45 \%$ & $70 \%$ & $70 \%$ \\
\hline & ND & ND & $52 \%$ & $44 \%$ & $77 \%$ & $67 \%$ \\
\hline \multirow{2}{*}{ Endrine } & ND & ND & $56 \%$ & $52 \%$ & $74 \%$ & $71 \%$ \\
\hline & ND & ND & $58 \%$ & $57 \%$ & $62 \%$ & $74 \%$ \\
\hline \multirow{2}{*}{ DDD } & ND & $\mathrm{ND}$ & $60 \%$ & $60 \%$ & $98 \%$ & $88 \%$ \\
\hline & ND & ND & $63 \%$ & $55 \%$ & $99 \%$ & $80 \%$ \\
\hline \multirow[t]{2}{*}{ Lindane } & ND & ND & $40 \%$ & $50 \%$ & $90 \%$ & $100 \%$ \\
\hline & ND & ND & $40 \%$ & $50 \%$ & $90 \%$ & $100 \%$ \\
\hline \multirow[t]{2}{*}{ Dieldrin } & ND & ND & $30 \%$ & $40 \%$ & $60 \%$ & $75 \%$ \\
\hline & ND & ND & $38 \%$ & $40 \%$ & $60 \%$ & $70 \%$ \\
\hline \multirow[t]{2}{*}{$\beta$-Endosulfan } & ND & ND & $40 \%$ & $45 \%$ & $65 \%$ & $80 \%$ \\
\hline & $\mathrm{ND}$ & ND & $20 \%$ & $30 \%$ & $60 \%$ & $70 \%$ \\
\hline \multirow{2}{*}{$\begin{array}{l}\text { Endosulfan } \\
\text { sulfate }\end{array}$} & ND & ND & $30 \%$ & $40 \%$ & $55 \%$ & $80 \%$ \\
\hline & ND & $\mathrm{ND}$ & $40 \%$ & $50 \%$ & $60 \%$ & $80 \%$ \\
\hline \multirow[t]{2}{*}{ DDT } & ND & $\mathrm{ND}$ & $30 \%$ & $40 \%$ & $60 \%$ & $70 \%$ \\
\hline & $\mathrm{ND}$ & ND & $40 \%$ & $45 \%$ & $55 \%$ & $70 \%$ \\
\hline
\end{tabular}

\section{SPME $\square$ LLE}

\section{Results and Discussions}

In this section, we present the obtained results and the corresponding discussions. The first step is to provide a comparative study.

\footnotetext{
Comparison of the yields of the two extraction methods

The extraction of OC by the LLE and SPME methods allowed us to calculate the yield of each molecule for each concentration of the two mixtures (Table 1). Among other, the studied chemical organochlorine molecules are Aldrine, DDE, DDD, Endrine, Lindane, Dieldrin, $\alpha / \beta$ Endosulfan Endosulfan sulfate and DDT.
}

It follows from these results that for the two lowest concentrations of 0.1 and $0.5 \mu \mathrm{g} / \mathrm{L}$, the extraction yield is zero for both used techniques. Only from the $1 \mu \mathrm{g} / \mathrm{L}$ concentration, we obtained a yield that varies from $36 \%$ to $100 \%$ for SPME and from 42 to $100 \%$ for LLE, respectively. In the present study, this concentration has been considered as a detection limit for the two extraction methods. More precisely, these values show that LLE generates identical yields as SPME, or even better.

Beyond such a detection limit, the results have shown that only Aldrin and DDD gave a yield of 97\% and $98 \%$ at $3 \mu \mathrm{g} / \mathrm{L}$ and a yield of $100 \%$ and $88 \%$ at $5 \mu \mathrm{g} / \mathrm{L}$ with the LLE method. For SPME, however, we obtained a yield of $100 \%$ and $90 \%$ for Aldrin and a 
yield of $99 \%$ and $80 \%$ for DDD at $3 \mu \mathrm{g} / \mathrm{L}$ and $5 \mu \mathrm{g} / \mathrm{L}$, respectively. These results show also that the extraction efficiency of the two methods increases when the concentration of OC increases from 1 to 3 $\mu \mathrm{g} / \mathrm{L}$, unlike the concentration of $5 \mu \mathrm{g} / \mathrm{L}$ where the yield stabilizes or even decreases in the majority of cases. It is noted that there is no difference between the two solutions as for the values of the yield for the two concentration 0,1 and $0,5 \mu \mathrm{g} / \mathrm{L}$, the yield remains null. However, for the concentrations 1, 2,3 and 5 $\mu \mathrm{g} / \mathrm{L}$, a certain difference has been observed when the values of the yield are more or less low compared to those of the mixture I. For the concentration $1 \mu \mathrm{g} / \mathrm{L}$, the yield is between 20 and $40 \%$ compared to the Mixture I, or the yield ranged from $38 \%$ to $63 \%$. The same remark is observed for the concentration $2 \mu \mathrm{g} / \mathrm{L}$ or the lowest value is $30 \%$ for not exceeding a yield of $50 \%$. While for Mixture I, 52\% was the lowest value. Only the Lindane showed a good yield that could reach $90 \%$ for LLE and SPME at the concentration of $3 \mu \mathrm{g} / \mathrm{L}$. For the other molecules, the yield remains low, and the corresponding values are closed in both techniques. The best yield does not exceed $65 \%$ obtained with LLE for $\beta$-Endosulfan and $60 \%$ with SPME. It was only from the $5 \mu \mathrm{g} / \mathrm{L}$ concentration that we were able to obtain a $100 \%$ yield with LLE and 95\% with SPME for Lindan and $80 \%$ with both methods for $\beta$-Endosulfan. For Endosulfan sulfate, we obtained $80 \%$ yield with LLE and $70 \%$ with SPME.

At this study level, a comparison of the two extraction methods shows that SPME provides slightly higher yields than LLE. These results remain unsatisfactory and do not give a clear benefit of SPME compared to the LLE. Especially, since the detection limit obtained by the two methods was considered too high, an optimization step was necessary before GCECD analysis of OC's.

\section{Optimization finding}

\section{Effect of adsorption Time}

In order to evaluate the influence of such a parameter on the yield, we immersed the fiber in the two solutions "Mixture I" and "Mixture II" at a concentration of $5 \mu \mathrm{g} / \mathrm{L}$, which allowed us to obtain the highest yield, for a period of 10;20;30 and 40 minutes at room temperature. Figure 1 shows the obtained results.

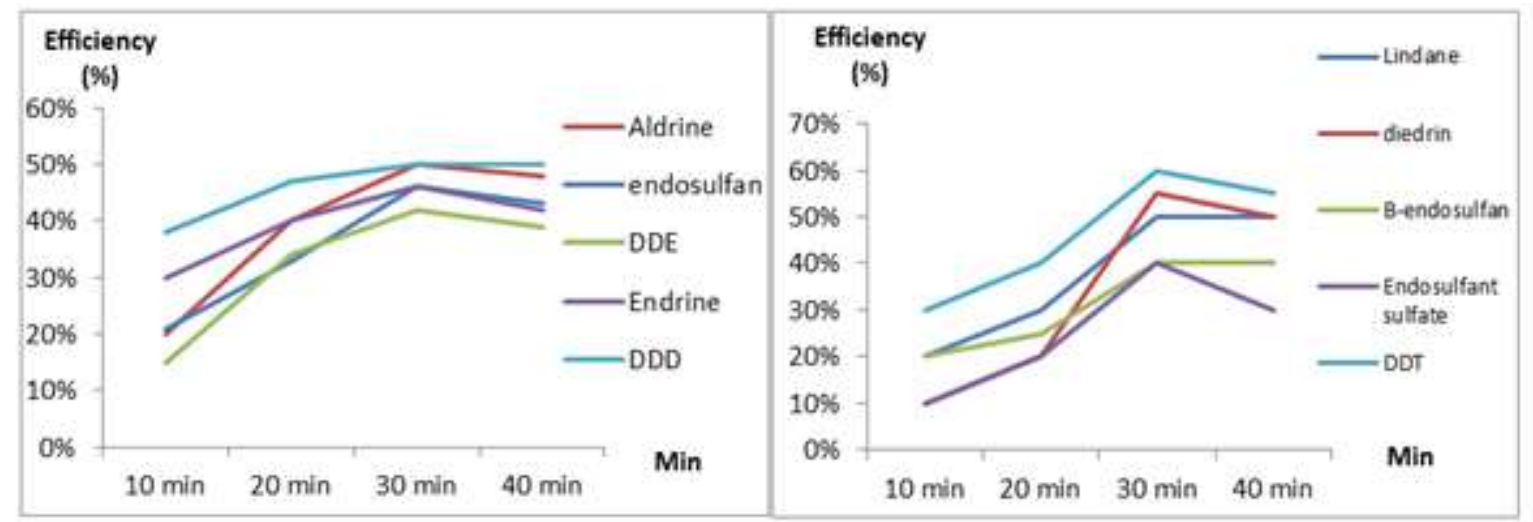

Figure 1. Performance of SPME as a function of exposure time for "Mixture I and II"

According to the results of such a figure, we observe an increase in the yield starting from 20 minutes with a yield which varies from $33 \%$ to $47 \%$. It was only after 30 minutes of exposure that we were able to reach the plateau with yields of $50 \%$ for Aldrin and DDD, $46 \%$ for Endosulfan and Endrin and $42 \%$ for DDE. Beyond this period, a stabilization is observed in general. This shows that $30 \mathrm{~min}$ of exposure is the optimal time allowing the fiber to effectively adsorb the analyzed products. For the "Mixture II" solution, a slight increase in yield started from 20 min with a $40 \%$ yield for DDT. We were able to achieve maximum yield only after 30 minutes of exposure with $60 \%$ DDT, $40 \%$ for $\beta$-Endosulfan and Endosulfan sulfate, $50 \%$ for Lindane, $55 \%$ for Dieldrin. Above 30 minutes, it is observed that the yield of DDT, Dieldrin, and Endosulfan sulfate began to decrease while it remained stable for Lindane and $\beta$-Endosulfan.

\section{Effect of time and agitation mode Ultrasonic agitation}

The effect of ultrasound agitation on the extraction performance has been studied. Stirring times range in length from 10 to 40 minutes. The associated results are presented in Figure 2. 


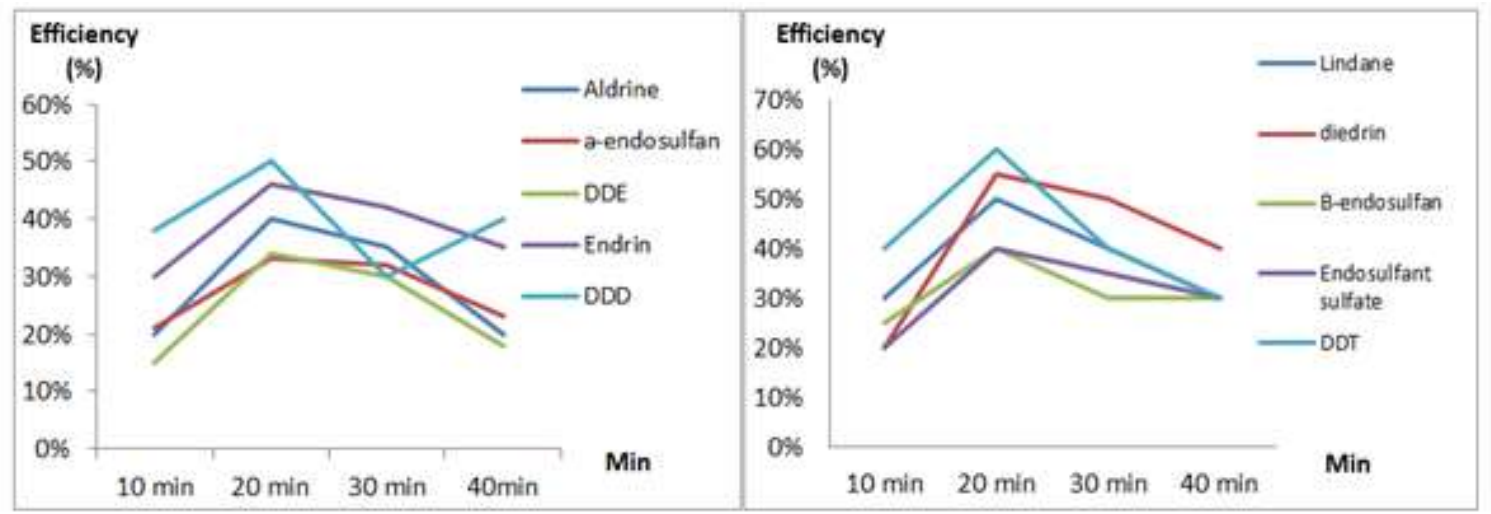

Figure 2. Performance of SPME as a function of ultrasound agitation time for "Mixture I and II"

It is remarked, from this Figure, that the performance of SPME after ultrasound stirring is optimum after stirring for 20 minutes with a yield of $53 \%$ for DDD, $48 \%$ for Endrin, $42 \%$ for Aldrin and $34 \%$ for DDE. and $\alpha$-endosulfan. Beyond this period, there is a significant decrease in the yield. For DDD, we went from $53 \%$ at $20 \mathrm{~min}$ to $30 \%$ at $30 \mathrm{~min}$ and from $42 \%$ to $35 \%$ for Aldrin. This behavior may be due to the micro-pulsations experienced by both the SPME fiber and the mixing solution which may be caused by a detachment of molecules, which are already fixed on the fiber. The same thing is observed for the Mixture II where the maximum of the yield was obtained after 20 minutes of stirring. For DDT, the yield is $60 \%$, while for the Dieldrin and Lindane the yield is $55 \%$ and $50 \%$, respectively. It is worth noting that $40 \%$ yield was observed for $\beta$-Endosulfan and Endosulfan sulfate. After 10 minutes, the yield decreased by $20 \%$ and then $10 \%$ for DDT. A slight decrease was shown up for Endosulfan sulfate. For Lindae, the yield decreased by $10 \%$ as the stirring time increased.

A close inspection reveals that the optimal absorption time did not correspond to the optimal time stirring in ultrasound. This pushed us to seek an alternative stirring approach.

\section{Stirring with a magnetic bar}

The study of the effect of stirring with magnetic stirring rods on the OC extraction was carried out by varying the agitation time from 10 to 40 minutes. The results for both mixtures are illustrated in Figure 3.

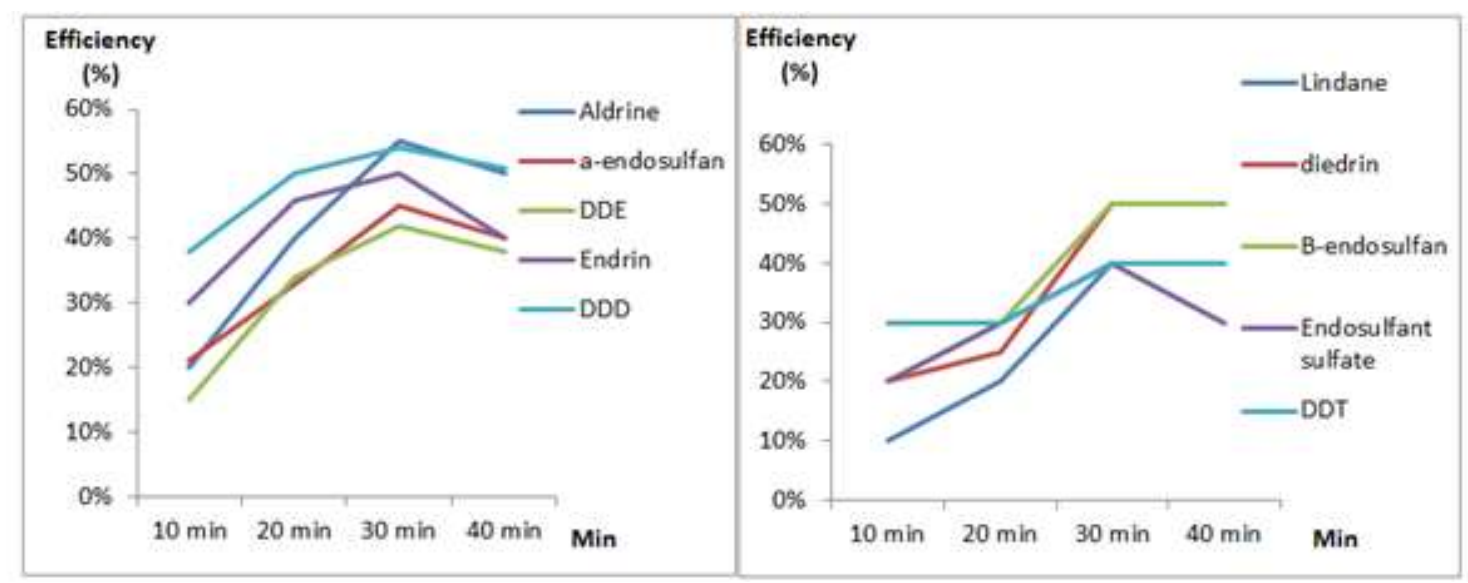

Figure 3. Performance of SPME as a function of magic stirring time for "Mixture I and II"

Fig. 3 indicates an increase in efficiency for all OC's from $10 \mathrm{~min}$ up to $30 \mathrm{~min}$. This is an optimal time which allowed us to obtain a $55 \%$ yield for Aldrin 54\% for DDD, 50\% for Endrin, $45 \%$ for DDE and $42 \%$ for $\alpha$-endosulfan. It shows that the magnetic rod stirring mode gives more relevant and satisfactory performance results than those with ultrasound. Moreover, it is observed that some curves are superimposed. The yield increased from $20 \%$ to $30 \%$ for $\beta$-Endosulfan and Endosulfan sulfate and from $10 \%$ to $20 \%$ for Lindane. It is remarked that $50 \%$ yield was obtained for Dieldrin and $\beta$-endosulfan. While, $40 \%$ yield was obtained for DDT, Endosulfan sulfate and Lindane after stirring for 30 minutes. Only the yield of Endosulfan sulfate decreased by $10 \%$ at 40 minutes. The comparison of the two agitation modes being adopted during this phase allowed us to opt for a time of $30 \mathrm{~min}$ for both the exposure time and the stirring time.

\section{Extraction temperature}

To investigate whether the temperature could have a beneficial effect on the sensitivity of the method, four temperatures $\left(10,20,30\right.$ and $\left.40^{\circ} \mathrm{C}\right)$ were tested for both mixture solutions at $5 \mu \mathrm{g} / \mathrm{L}$. The immersion time of the fiber and stirring at the 30-minute magnetic bar were maintained. The obtained results are illustrated in Figure 4. 


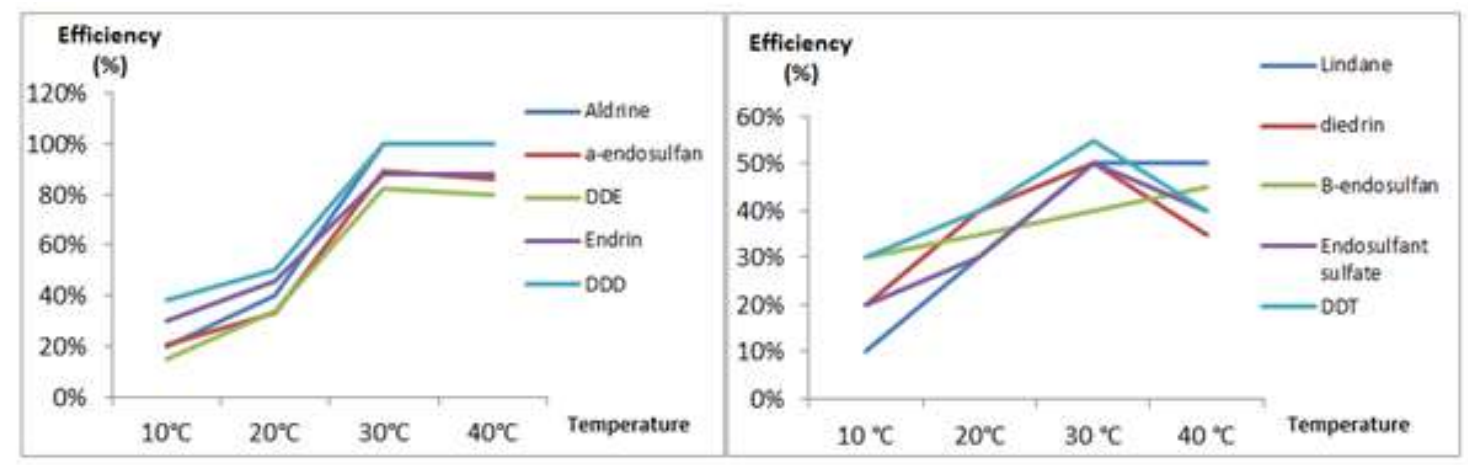

Figure 4. Performance of SPME as a function of temperature for "Mixture I and II"

It follows from Fig. 4 that the yield increases as a function of temperature to reach its maximum at $30^{\circ}$ C with a yield of $100 \%$ for Aldrin and DDD, $89 \%$ for $\alpha$-endosulfan, $88 \%$ for Endrin and $82 \%$ DDE. These values correspond to the maximum yield. Beyond 40 ${ }^{\circ} \mathrm{C}$, the yield is stable. It is remarked that the yield increases proportionally to the temperature to reach its maximum at $30{ }^{\circ} \mathrm{C}$ with a yield of $55 \%$ for DDT, $50 \%$ for Endosulfan sulfate, Lindane and Dieldrin. An increase of only $5 \%$ was observed for $\beta$-Endosulfan which goes from $30 \%, 35 \%, 40 \%$, to $45 \%$ after 10,20 , 30 and $40^{\circ} \mathrm{C}$. Above $40^{\circ} \mathrm{C}$, the yield decreases except for Lindane.

\section{Optimization by $\mathbf{P H}$ control}

It is noted that PH could play an important role in the behavior of the SPME fiber interacting with chemical composites. By promoting and accelerating the transfer of the chemical elements to the extracting phase, we can get a recovery value of the coating fiber promoting the fixation of certain molecules in acidic media including other ones in basic media. However, this may generate a problem concerning yield in the quantification of the mixture present because of the competition for binding between the different molecules appeared in the mixture. The relevant feature is to have a mixture with a neutral $\mathrm{pH}$ leading to better separation and precise quantification of the different molecules present in the mixture in question.

We first measured the $\mathrm{pH}$ of the two solutions "Mixture I" and "Mixture 2" at different concentrations. Then, we varied the $\mathrm{pH}$ of the extractions from the doping of water by the two mixture (I and II). The values are measured at a temperature of $20^{\circ} \mathrm{C}$.

It has been found that the best returns are obtained at neutral PHs. It is remarked that the $\mathrm{pH}$ is a primordial parameter that must be taken into account allowing a better extraction, as well as the profitability of the yield.

\section{Optimization by ionic strength}

The extraction is often limited for water-soluble pesticides because of their low affinity associated with the fiber. By increasing the ionic strength of a solution, the fixation speed of the chemical molecules presented in the mixture interacting with the coating of the SPME fiber can be promoted or disadvantaged.

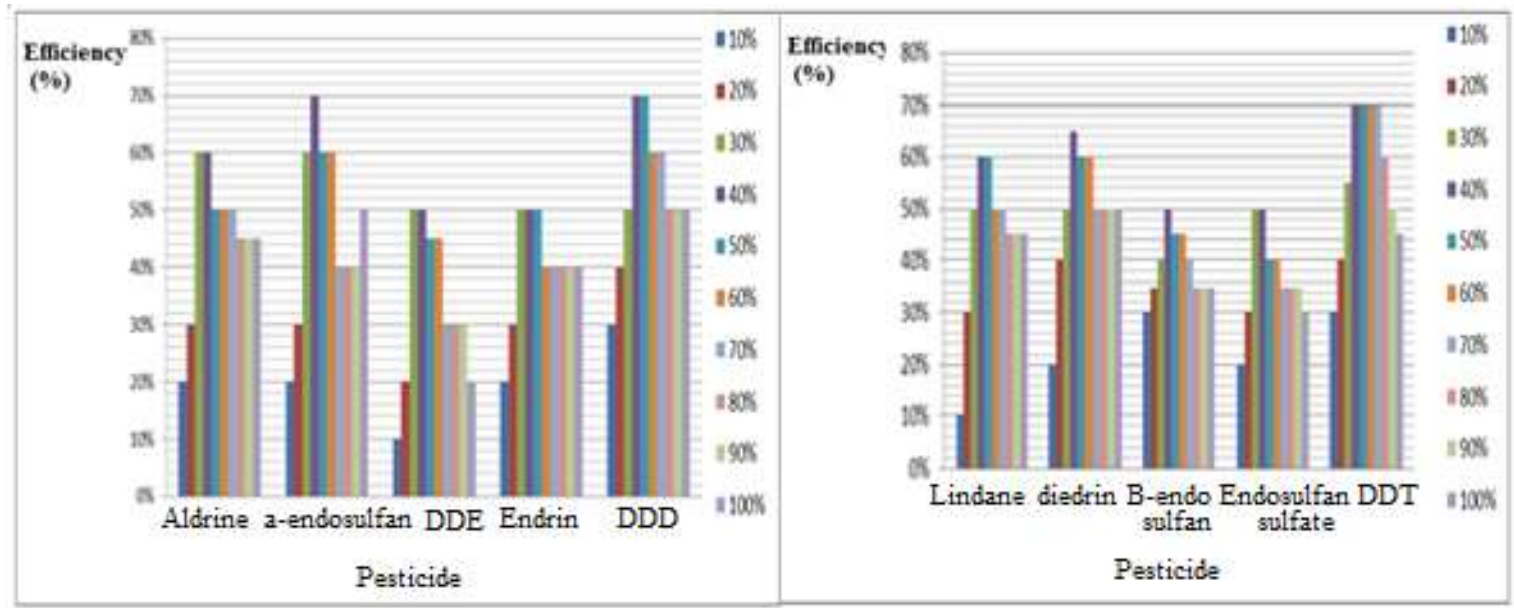

Figure 5. Performance of SPME as a function of salinity for "Mixture I and II"

To obtain a good extraction, it is, therefore, necessary to find an exact amount of salt added to the solution. To do so, we added different amounts of sodium hydroxide to a solution of $100 \mathrm{~mL}$ of hexane until saturation $(100 \%)$ with a $10 \%$ plateau. These solutions were used to dilute both at a concentration of $5 \mu \mathrm{g} / \mathrm{L}$. The results are shown in Figure 5 . 
It is observed that the obtained extraction yields vary from one saturation stage to another. At $30 \%$ saturation, we got $60 \%$ yield for Aldrin and $\alpha$ Endosulfan and 50\% for DDE, Endrin and DDD to achieve a $60 \%$ yield for Aldrin $70 \%$ for $\alpha$-Endosulfan. and the DDD at $40 \%$ saturation. It is remarked that this saturation value allows a better extraction. For certain OC's, the addition of a solution beyond $70 \%$ extraction decreases for DDE. For the Mixture II, it is noted that $70 \%$ of yield could be reached at $40,50,60$ and $70 \%$ saturation for DDT, For Lindane and
Dieldrin, the yield is $60 \%$ after 40 and $50 \%$ saturation. However, it is shown that the optimal yields are reached from $40 \%$. For saturations below $40 \%$, the extraction is weak. A percentage of $40 \%$ of $\mathrm{NaOH}$ was retained for the rest of the present study.

\section{Results from validated optimization settings}

We again compared the performance of the LLE and the SPME by respecting the previously optimized parameters for SPME. The performance results for both methods are presented in Table II.

Table II. Efficiency of the LLE and SPME method after optimization.

\begin{tabular}{|c|c|c|c|c|c|c|}
\hline Conc $(\mu \mathrm{g} / \mathrm{L})$ & 0.1 & 0.5 & 1 & 2 & 3 & 5 \\
\hline \multirow{2}{*}{ Aldrine } & $\mathrm{ND}$ & $\mathrm{ND}$ & $45 \%$ & $60 \%$ & $97 \%$ & $100 \%$ \\
\cline { 2 - 7 } & $34 \%$ & $44 \%$ & $56 \%$ & $82 \%$ & $100 \%$ & $100 \%$ \\
\hline \multirow{3}{*}{$\alpha$-endosulfan } & $\mathrm{ND}$ & $\mathrm{ND}$ & $42 \%$ & $56 \%$ & $78 \%$ & $80 \%$ \\
\cline { 2 - 7 } & $23 \%$ & $33 \%$ & $63 \%$ & $90 \%$ & $89 \%$ & $80 \%$ \\
\hline \multirow{2}{*}{$\mathrm{DDE}$} & $\mathrm{ND}$ & $\mathrm{ND}$ & $50 \%$ & $45 \%$ & $70 \%$ & $70 \%$ \\
\cline { 2 - 7 } & $25 \%$ & $40 \%$ & $60 \%$ & $68 \%$ & $82 \%$ & $90 \%$ \\
\hline \multirow{2}{*}{ Endrine } & $\mathrm{ND}$ & $\mathrm{ND}$ & $56 \%$ & $52 \%$ & $74 \%$ & $71 \%$ \\
\cline { 2 - 7 } & $25 \%$ & $48 \%$ & $72 \%$ & $69 \%$ & $88 \%$ & $91 \%$ \\
\hline \multirow{2}{*}{ DDD } & $\mathrm{ND}$ & $\mathrm{ND}$ & $60 \%$ & $60 \%$ & $98 \%$ & $88 \%$ \\
\cline { 2 - 7 } & $32 \%$ & $45 \%$ & $80 \%$ & $80 \%$ & $100 \%$ & $98 \%$ \\
\hline \multirow{2}{*}{ Lindane } & $\mathrm{ND}$ & $\mathrm{ND}$ & $40 \%$ & $50 \%$ & $90 \%$ & $100 \%$ \\
\cline { 2 - 7 } & $10 \%$ & $25 \%$ & $60 \%$ & $75 \%$ & $90 \%$ & $95 \%$ \\
\hline \multirow{2}{*}{ Dieldrin } & $\mathrm{ND}$ & $\mathrm{ND}$ & $30 \%$ & $40 \%$ & $60 \%$ & $75 \%$ \\
\cline { 2 - 7 } & $20 \%$ & $30 \%$ & $50 \%$ & $60 \%$ & $75 \%$ & $90 \%$ \\
\hline \multirow{2}{*}{$\mathrm{B}-$-endosulfan } & $\mathrm{ND}$ & $\mathrm{ND}$ & $40 \%$ & $45 \%$ & $65 \%$ & $80 \%$ \\
\cline { 2 - 7 } & $20 \%$ & $25 \%$ & $40 \%$ & $60 \%$ & $80 \%$ & $80 \%$ \\
\hline \multirow{2}{*}{ Endosulfan sulfate } & $\mathrm{ND}$ & $\mathrm{ND}$ & $30 \%$ & $40 \%$ & $55 \%$ & $80 \%$ \\
\cline { 2 - 7 } & $20 \%$ & $30 \%$ & $55 \%$ & $65 \%$ & $80 \%$ & $82 \%$ \\
\hline \multirow{2}{*}{ DDT } & $\mathrm{ND}$ & $\mathrm{ND}$ & $30 \%$ & $40 \%$ & $60 \%$ & $70 \%$ \\
\cline { 2 - 6 } & $30 \%$ & $40 \%$ & $60 \%$ & $70 \%$ & $100 \%$ & $100 \%$ \\
\hline
\end{tabular}

\section{SPME $\square$ LLE}

It is recalled that that before the optimization of the SPME extraction conditions the yield at the concentration 0.1 and $0.5 \mu \mathrm{g} / \mathrm{L}$ was zero. After optimization, the detection threshold is improved, and the whole chemical composite is detected.

OC's at $0.1 \mu \mathrm{g} / \mathrm{L}$ with $20 \%$ and $30 \%$ yields for Dieldrin and Endosulfan sulfate, $23 \%$ and $33 \%$ for $\alpha$ endosulfan, $25 \%$ and $40 \%$ for DDE, $25 \%$ and $48 \%$, respectively are recovered.

For Endrin, $30 \%$ and $40 \%$ for DDT, $32 \%$ and $45 \%$ for DDD, $34 \%$ and $44 \%$ for Aldrin, respectively at $0.1 \mu \mathrm{g} / \mathrm{L}$ and $0.5 \mu \mathrm{g} / \mathrm{L}$ are found.

A significant evolution of the yield for all pesticides from $1 \mu \mathrm{g} / \mathrm{L}$ with a yield of $60 \%, 75 \% 90 \%$ and $95 \%$ for Lindane, $80 \%, 80 \%, 98 \%$ and $100.28 \%$ for DDD, $72 \%, 69 \%, 88 \%$ and $91 \%$ for Endrin, $60 \%$, $68 \%, 82 \%, 90 \%$ for DDE, $63 \%, 90 \%, 89 \%, 80 \%$ for $\alpha$-endosulfan, $60 \%, 70 \%, 100.28 \%$ and $100 \%$ for DDT, $56 \%, 82 \%, 100.28 \%$ and $100.28 \%$ for Aldrine, respectively at $1 \mu \mathrm{g} / \mathrm{L}, 2 \mu \mathrm{g} / \mathrm{L}, 3 \mu \mathrm{g} / \mathrm{L}$ and $5 \mu \mathrm{g} / \mathrm{L}$ is computed. For all tested concentrations, these values indicate that the adsorption is relevant with a better performance. The associated result is shown in Figure 6.

A comparison between the obtained yields before optimization and after optimization of the SPME shows that the optimization of this method is relevant to get higher yields with a yield of $100 \%$ instead of $90 \%$ for the Aldrin and $100 \%$ for the instead of $70 \%$ for DDT at $5 \mu \mathrm{g} / \mathrm{L}$. These yields range from $10 \%$ to $34 \%$ for Lindane and Aldrine at $0.1 \mu \mathrm{g} / \mathrm{L}$ compared to the zero values obtained before optimization.

It should be noted that these conditions are specific to detect OC's in order to detect using SPMD fiber in the water matrix. These conditions can therefore vary according to the analyzed molecules and the matrix used. It is recalled that Merib et al. reported in a study that the water matrix for the extraction of OC molecules (Aldrin, Dieldrin and Lindane) where the maximum extraction was obtained at a temperature of $60^{\circ} \mathrm{C}$ and an adsorption time of $40 \min ^{16}$. 


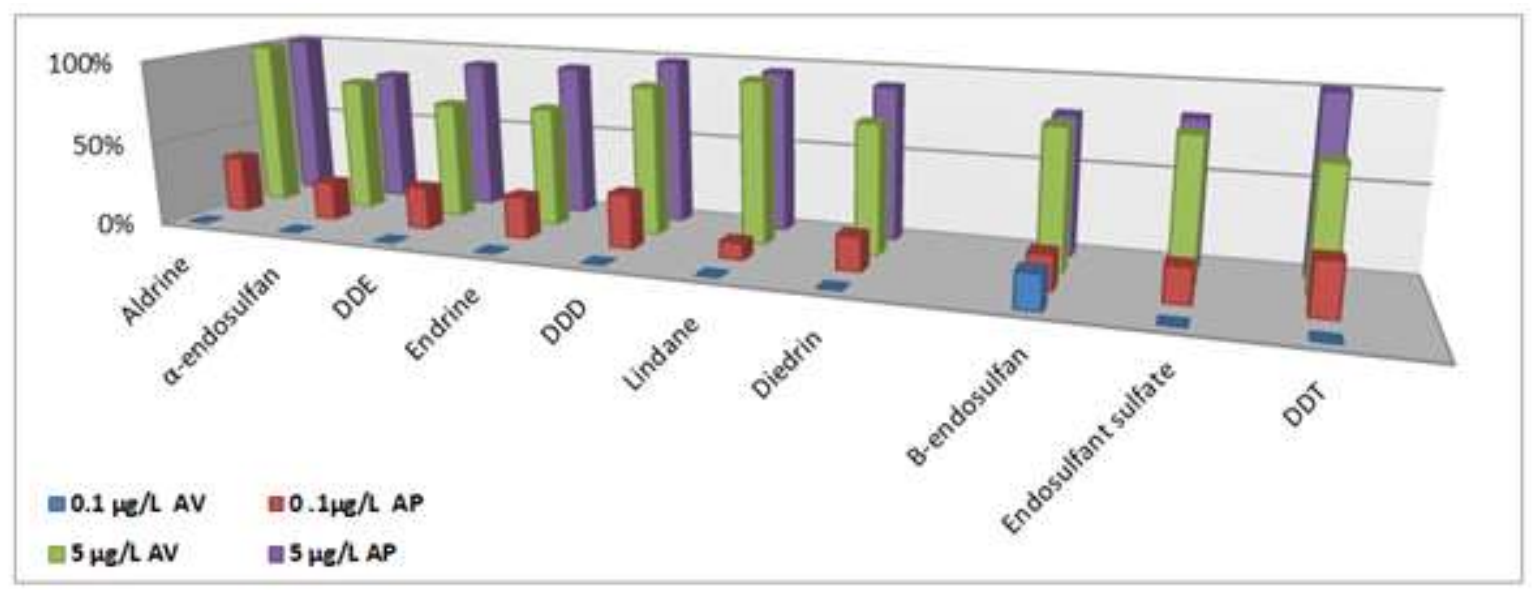

Figure 6. Comparison between yield values before and after optimization

In another study, Rada et al. worked on the soil matrix and found that an extraction time of $30 \mathrm{~min}$ was better for their extraction [4]. Moreover, Scheyer in [7] has set a $40 \mathrm{~min}$ extraction time and a temperature of $45{ }^{\circ} \mathrm{C}$, which represents a good compromise for optimal extraction of the most OC pesticides (DDD, DDE, Aldrin, Endrin, $\alpha$ endosulfan), although some molecules remain too weakly extracted.

However, in the present study, the optimization of the SPME allowed us to improve by 10 times the detection threshold which went from $1 \mu \mathrm{g} / \mathrm{L}$ (before optimization) to $0.1 \mu \mathrm{g} / \mathrm{L}$ (after optimization). Thus, a yield that varies from $10 \%$ to $34 \%$ for all OC at 0.1 $\mu \mathrm{g} / \mathrm{L}$ is observed. It should be noted that LLE extracted samples did not detect OC's at this concentration. We also found a real increase in performance for each analyzed OC for all tested concentrations. In this regard, the Aldrin, the DDD and the DDT recorded a yield of $100 \%$ as of the concentration $3 \mu \mathrm{g} / \mathrm{L}$. For the other pesticides, and at 5 $\mu \mathrm{g} / \mathrm{L}$, the yield is $90 \%$ for Dieldrin and DDE, $91 \%$ for Endrin, $95 \%$ for Lindane and $98 \%$ for DDD. A rather close yield was observed for $\alpha$ and $\beta$-endosulfan with $80 \%$ and $82 \%$ for Endosulfan sulfate at the concentration of $5 \mu \mathrm{g} / \mathrm{L}$. These values are higher than those obtained by the LLE. A comparison between the SPME yield values before and after optimization reveals that various parameters including, temperature, adsorption time and stirring time, $\mathrm{pH}$ effect and salt addition influence the quality of the extraction, considerably improve the extraction yield by SPME method. They made it possible to obtain exploitable results with a good yield which could reach $100 \%$ for Aldrin, DDD and DDT. It has been considered higher for all the OC's tested compared to those obtained before optimization.

Based on these results, we can say that SPME is an interesting and logical alternative method to LLE. It meets the needs of modern analysis laboratories regarding accuracy, efficiency, speed, reliability and economy as well as the environment respect.

\section{Conclusions}

In this paper, we have studied two different methods of the OC extraction namely solid phase microextraction (SPME), and liquid-liquid extraction (LLE) coupled to the gas chromatography with electron detectors (GC-ECD) to determine OC's in the water samples. We have verified and optimized different parameters in order to get the ideal temperature extraction, adsorptive time, duration and agitation mode, $\mathrm{pH}$ effect and salt addition. The obtained results have been elaborated from 30 minutes, duration of immersion, a stirring mode of 30 minutes with stir bar stirring, and a temperature of 30 degrees Celsius. In particular, the SPME extraction mode, adapted to the nature of the water samples, has been optimized to develop the extraction process. It has been shown that this method can improve the detection and quantification of OCs even in the trace. The corresponding optimization had made it possible to go from a detection limit (LD) of $1 \mu \mathrm{g} / \mathrm{L}$ to $0.1 \mu \mathrm{g}$ / L. When this optimized method is applied, it has been revealed that it can be used to allow the detection of pesticides in the mixing solution even in the very low concentrations $(0.1,0.5 \mu \mathrm{g} / \mathrm{L})$. Then, we have given a comparative study between the results of the yield of the LLE extraction method and the SPME before and after adopting the optimized parameters revealing that this extraction technique is considered as a useful method in Morocco for dealing with the pesticide residues in water samples.

\section{References}

1- C. Blasco, M. Fernández, Y. Picó, G. Font, Comparison of solid-phase microextraction and stir bar sorptive extraction for determination six organophosphorus insecticides in honey by liquid chromatography-mass spectrometry, Journal of Chromatography A, 1030, 2004,77-85.

2- R.I. Bonansea, M.V. Amé, D.A. Wunderlin, Solid-phase microextraction and gas chromatography with mass spectrometric detection for the determination of pesticides in 
aqueous samples, Journal of Chromatography A, 795, 2013, 105-115.

3- C. L. Arthur, J. Pawliszyn, Solid Phase Microextraction with thermal desorption using fused silica optical fibers, Analytical Chemistry, 62, 1990, 2145-2148.

4- R. A. Dong, P. L. Liao, Determination of organochlorine pesticides and their metabolites in soil samples using headspace solid-phase microextraction, Journal of Chromatography A, 918, 2001, 177-188.

5- C. P. Dougherty, S. H. Hlotz, J. C. Reinert, L. Panyacosit, D. A. Axelrad, T. J. Woodruff, Dietary exposures to food contaminants across the United States, Environmental Research, 84, 2000, 170-180.

6- J. H. Jelen, M. Majcher, M. Dziadas, Multiresidue detection of pesticides in juice and fruit wine: A review of extraction and detection methods, Food Research International, 46, 2012, 399-409.

7- R. P. Berladi, J. Pawliszyn, The application of chemically modified fused silica fibers in the extraction of organics from water matrix samples and their rapid transfer to capillary columns Environmental Science and Pollution Research, 24 .1989. 179-191.

8- R. Botter, G. Bouchoux, Techniques de l'ingénieur, Spectrométrie de masse, Determination of chlorinated pesticides in water by SPME/GC, Water Research, 36, 2002, 1909-1911.

9- H. Shahsavand, M. R. Nateghi, Analysis of chlorothalonil and degradation products in soil and water by GC/MS and LC/MS. Chemosphere, Journal of Water Chemistry and Technology,04,2018, 86-90.

10- S. Chen, S. Lili, S. Zhengjun, H. Qiuhui, Determination of organochlorine pesticide residues in rice and human and fish fat by simplified two-dimensional gas chromatography, Food Chemistry, 104, 2007, 1315-1319.

11- C. De Rossi, R. Bierl, J Riefstahl, Organic pollutants in precipitation: monitoring of pesticides and polycyclic aromatic hydrocarbons in the region of Trier (Germany), Physics and Chemistry of the Earth, 28, 2003, 307-314.

12- A. Derouiche, M. R. Driss, J. P. Morizur, M.H. Taphanel, Simultaneous analysis of polychlorinated biphenyls and organochlorine pesticides in water by headspace solid-phase microextraction with gas chromatography-

21- A. Yang, J. Zhao, J. Wang, H. Yu, H. Piao, D. $\mathrm{Li}$, Water-based gas purge microsyringe extraction coupled with liquid chromatography for determination of alkylphenols from sea food Laminaria japonica Aresh, Journal of Chromatography A , 1300, 2018, 302-360. tandem mass spectrometry, Journal of Chromatography A, 1138, 2007, 231-300.

13- M. Fernández, C. Padrón, L. Marcon, S. Ghini, R. Colombo, A. G. Sabatini, S. Girotti, Determination of organophosphorus pesticides in honeybees after solid-phase microextraction, Journal of Chromatography A, 922, 2001, 257-265

14- C. Ferrer, M. J. Gómez, J. F. García-Reyes, I. Ferrer, E. M. Thurman, A.R. Fernández-Alba, Determination of pesticide residues in olives and olive oil by matrix solid-phase dispersion followed by gas chromatography/mass spectrometry and liquid chromatography/tandem mass spectrometry, Journal of Chromatography A, 1069, 2005, 183-194.

15- J. Fillion, F. Sauvé, J. Selwyn, a Multiresidue method for the determination of residues of 251 pesticides in fruits and vegetables by gas chromatography/mass spectrometry and liquid chromatography with fluorescence detection, Journal of AOAC INTERNATIONAL, 83, 2000, 698-750.

16- H. Shahsavand, M. R. Nateghi, Solid Phase Extraction and Flame Atomic Absorption Determination of Cadmium in Water Samples, Journal of Water Chemistry and Technology, 2018, 86-90.

17- S.A. Harris, M.J. Whiticar, M.K. Eek, Molecular and isotopic analysis of oils by solid phase microextraction of gasoline range hydrocarbons, Organic Geochemistry 30, 1999, 721-737

18- F. Hernández, O. J. Pozo, J. V. Sancho, L. Bijlsma, M. Barreda, E. Pitarch, Multiresidue liquid chromatography-tandem mass spectrometry determination of 52 non gas chromatography-amenable pesticides and metabolites in different food commodities, Journal of Chromatography A, 1109, 2006, 242-252.

19- M.C. Sampedro, O. Martin, C. Lopez de Armentia, M.A. Goicolea, E. Rodriguez, Z. Gomez de Balugera, J. Costa-Moreira, R. J. Barrio, Solid-phase microextraction for the determination of systemic and non-volatiles pesticides in river water using gas chromatography with nitrogen-phosphorous and electron-capture detection, Journal of Chromatography A, 893, 2000, 347-358.

20- F. J. Santos, M. T. Galceran, The application of gas chromatography to environmental analysis Trends in Analytical Chemistry. 2, 2002, 672-685.

22- J.G. Eskenazi, E. A. Gladstone, A. Bradman, L. Pedersen, C. Johnson, D. B. Barr, Scientific Reports volume 8., Association between in utero organophosphate pesticide exposure and abnormal reflexes in neonates, NeuroToxicology, 26, 2018, 1167-1180. 